\title{
OS INCENTIVOS FISCAIS NO BRASIL
}

ROCCO ANTONIO RANGEL ROSSO NELSON

INSTITUTO FEDERAL DO RIO GRANDE DO NORTE IFRN, CÂMPUS JOÃO CÂMARA

BRASIL

"Siempre es el momento apropiado para hacer lo que es correcto".

Martin Luther King. 


\title{
RESUMO
}

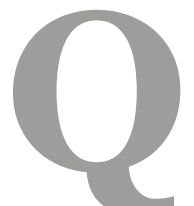

uando do estudo do plexo normativo tributário, no Brasil, depara-se com uma lacuna jurídica, no que tange ao enquadramento e ao próprio conceito jurídico de incentivo fiscal. A pesquisa em tela, fazendo uso de uma metodologia de análise qualitativa, usando-se os métodos de abordagem hipotético-dedutivo de caráter descritivo e analítico, tem por linha de fundo ofertar algumas premissas basilares sobre a configuração normativa dos incentivos fiscais, vindo a reconhecer que o correto uso dessa forma de intervenção do Estado na economia, pode fomentar o desenvolvimento de direitos como da cultura, educação, saúde, sustentabilidade ambiental, desenvolvimento regional, dentre outros ditames constitucionais.

Palavras-chave: incentivos fiscais, desoneração tributária, norma indutora, extrafiscalidade.

\begin{abstract}
When studying the complex regulatory tax in Brazil is facing a legal loophole, in regard to the legal framework and the very concept of tax incentives. Research on screen, making use of a method of qualitative analysis, using the methods of hypothetical-deductive approach of descriptive and analytical character, is the bottom line offer some basic assumptions about the normative design of the tax incentives, come to recognize the correct use of this form of state intervention in the economy, can foster the development of rights as culture, education, health, environmental sustainability, regional development, among other constitutional provisions.
\end{abstract}

Keyword: tax incentives, tax relief, standard inductor, extrafiscality.

\section{RESUMEN}

Cuando se estudia el plexo normativo tributario, en Brasil, surge un vacío jurídico, en lo que respecta al marco legal y el concepto mismo de incentivo fiscal. La investigación que se presenta, haciendo uso de un método de análisis cualitativo, utilizando los métodos de abordaje hipotético-deductivos de carácter descriptivo y analítico, tiene por línea de fondo ofrecer algunos supuestos básicos sobre la configuración normativa de los incentivos fiscales, llegando a reconocer que el uso adecuado de este tipo de intervención estatal en la economía, puede fomentar el desarrollo de los derechos como de la cultura, la educación, la salud, la sustentabilidad del ambiente, el desarrollo regional, entre otros mandatos constitucionales.

Palabras Clave: incentivos fiscales, desgravación fiscal, inductor estándar, extrafiscalidad. 


\section{DAS CONSIDERAÇÕES INICIAIS}

O exercício financeiro do Estado é desenvolvido como meio para que este possa prestar as atividades em benefício da sociedade e atingir os fins esculpidos nas normas constitucionais.

No contexto do momento político-econômico, em que passa o Estado, afere-se que a figura do tributo é a principal fonte de receita para subsidiar suas atividades.

(...) quadro da evolução dos modelos de financiamento do Estado, importa ressaltar que o agigantamento do Estado passou a ser questionado quando se passou a considerar que seu crescimento já não era garantia de melhor distribuição de renda ou de eficiência econômica. Estes objetivos, conquanto permanentes, não se alcançam sem o concurso da iniciativa privada, a quem há de ser reservado um espaço para atuação. O Estado Fiscal social cede espaço para o Estado do século XXI, denominado ‘Estado Democrático e Social de Direito’ (ou Estado Subsidiário, ou Estado da Sociedade de Risco, ou Estado de Segurança). Marcam-no uma diminuição de tamanho e restrição a seu intervencionismo. É Estado Fiscal, ainda de maneira mais marcante, uma vez que as privatizações diminuem os recursos provenientes de seus esforços (SCHOUERI, 2013, p. 39).

Não só isso, constituindo, também, uma das principais formas de intervenção no domínio econômico, onde uma maior oneração ou desoneração tributária pode vim a induzir comportamentos por parte da entidade privada, ${ }^{1}$ promovendo ou obstaculizando o feixe de direitos e programas constitucionais, onde o tributo se estenderia além de uma função fiscal ${ }^{2}$.

(...) são utilizados com função extrafiscal, isto e, como instrumentos para a intervenção do Estado na atividade econômica, e, em muitas situações, devem ser manejados com rapidez, para que possam produzir a intervenção necessária. Assim, os defensores da utilização dos tributos com função extrafiscal dizem que estes devem ser flexíveis, no sentido de poderem ser alterados sem a demora que decorreria da estrita obediência aos princípios constitucionais da tributação; especialmente aos princípios da legalidade e da anterioridade. Por isto e que esses princípios não se aplicam plenamente aos impostos ditos regulatórios, ou dotados

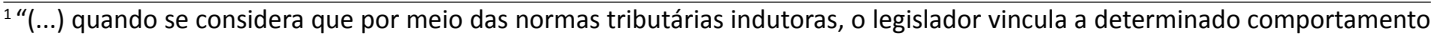
um consequente, que poderá consistir em vantagem (estimulo) ou agravamento de natureza tributária, por meio de um corte, quando se extraem determinações individualizadas (...)" (SCHOUERI, 2005, p. 40).

2 “(...) impõe que se perceba que o tributo tem várias funções. Ao lado da mais óbvia - a arrecadadora - destacam-se outras, comuns a toda a atividade financeira do Estado (receitas e despesas): as funções distributivas, alocativa (indutora) e estabilizadora. Ao afetar o comportamento dos agentes econômicos, o tributo poderá influir decisivamente no equilíbrio antes atingido pelo mercado. As distorções daí decorrentes também haverão de ser consideradas na análise da tributação" (SCHOUERI, 2013, p. 36).
} 
de função extrafiscal, entre os quais podem ser citados os impostos de importação, de exportação e sobre operações financeiras (MACHADO, 2010, p. 39)

É nesse bojo da extrafiscalidade do tributo, que com fim de atingir outros fins que não o de arrecadação ${ }^{3}$, por meio da indução do comportamento do cidadão e do empresariado ${ }^{4}$, insere-se a chamada teoria dos incentivos fiscais ${ }^{5}$.

Sobre a função alocativa do tributo, ou seja indutora, explicita o professor SCHOUERI (2011):

(...) quando se tem em conta que a própria incidência do tributo não é neutra sobre a economia, pois acaba por ter reflexos na forma como a totalidade dos recursos é dividida para utilização no setor pública e no setor privado. Reflexo da função alocativa, tem-se a indução de comportamentos. Afinal, a tributação se vincula a comportamentos humanos e a incidência tributária passa a ser um fator a ser considerado na própria decisão do agente econômico; (...) (p. 37).

A figura dos incentivos fiscais é um instrumento de clara extrafiscalidade ${ }^{6}$. Em virtude da ausência de dispositivo legal que traçasse sua definição e formas de manifestação ${ }^{7}$, tem seus fundamentos construídos doutrinariamente ${ }^{8}$.

Destaca, o professor CATÃO (2004), quanto do uso impreciso da terminologia incentivos fiscais:

Há sem dúvida na doutrina, no ordenamento positivado, inclusive constitucional, e especialmente nos meios econômicos, políticos e até entre os leigos, o uso dessa expressão com uma razoável imprecisão quanto à caracterização de um incentivo fiscal, especialmente quando se trata de adequação ao princípio da capacidade contributiva (pp. 51-52)9.

\footnotetext{
${ }^{3}$ Sobre incentivos fiscais: "Pelo seu objetivo, de pronto, diga-se constituir esta desoneração um caso típico de extrafiscalidade" (SILVA \& MOTTA FILHO, 2010, p. 331).

4 "Dessa forma, a extrafiscalidade poder ser concretizada através das chamadas normas tributárias indutoras, por meios de incentivos fiscais ou agravamentos tributários, (...)" (ELALI, 2010, p. 56).

5 “(...) Em particular, as normas indutoras, quando veiculam incentivos, tem uma importância fundamental na redução das desigualdades regionais e sociais" (...) (ELALI, 2007, p. 29).

6 “(...) Os incentivos fiscais estão no campo da extrafiscalidade, que, como ensina Geraldo Ataliba, é o emprego dos instrumentos tributários para fins não fiscais, mas ordinatórios (isto é, para condicionar comportamentos de virtuais contribuintes, e não, propriamente, para abastecer de dinheiro os cofres públicos). (...)" (CARRAZZA, 2013, p. 988).

7 "Não devemos confundir os incentivos fiscais (também chamados benefícios fiscais ou estímulos fiscais) com as isenções tributárias. Estas são, apenas, um dos meios de concedê-los. (...)" (CARRAZZA, 2013, p. 988).

8 "Tarefa das mais complexas consiste em unificar os conceitos emitidos por autores brasileiros ao tratarem de incentivos fiscais. (...)" (PIRES, 2007, p. 19).

9 "A própria legislação brasileira emprega indistintamente os termos incentivo, estímulo e prêmio, (...). Por isso é que auxílios tributários, benefícios fiscais e despesas fiscais são noções estreitamente ligadas entre si” (ELALI, 2007, p. 121).
} 
Não há dúvidas que essa lacuna legal traz obscuridade e insegurança jurídica quando das formulações das políticas tributárias, quando a aferição do tratamento jurídico a ser dado, pois torna-se fulcral conhecer a natureza jurídica dos incentivos fiscais, para o seu enquadramento e, consequentemente, devido tratamento jurídico ${ }^{10}$.

Sobre o limbo conceitual, no que tange aos incentivos fiscais, o professor RODRIGUES (2007), explicita:

Vale observar que a imprecisão no que toca à definição das espécies de incentivos permite confundi-las com a não-incidência legal e constitucional ou, até mesmo, com a imunidade do mínimo existencial. Parece-nos que o proprio legislador constitucional lança mão dessas espécies sem se preocupar em defini-las ou hierarquizá-las, (...) (pp. 19-20).

Assevera que a matéria, ora tratada, não consta de uma sistematização via norma constitucional. Em caráter infraconstitucional a lei de responsabilidade fiscal (lei complementar $\mathrm{n}^{0}$ 101/o2), versa, apenas sobre os limites dos incentivos fiscais, em um âmbito de gestão orçamentária ${ }^{11}$.

\section{INCENTIVOS FISCAIS}

É fulcral constituir a premissa que o direcionamento teleológico dos incentivos fiscais dar-se de acordo com o paradigma estatal em vigência.

Quando do Estado Social, cunhado sobre os pilares do pensamento econômico de Keynes, tem-se a figura dos incentivos fiscais como algo imprescindível ao desenvolvimento econômico ${ }^{12}{ }^{13}$. A política fiscal era baseada "na ideia de desenvolvimento movido à custa do dinheiro do Estado" (TORRES, 2005, p. 134).

\footnotetext{
$\overline{10 ~ “(. . .) ~ i m p e n d e ~ s a b e r ~ d a ~ e f e t i v i d a d e ~ o u ~ f i n a l i d a d e ~ e m ~ s e ~ p r e c i s a r ~ c o n c r e t a m e n t e ~ u m ~ c o n c e i t o ~ d o u t r i n a ́ r i o ~ o u ~ l e g a l ~ q u e ~ p e r m i t a ~}$ assinalar com perfeição a figura genericamente concebida de incentivo fiscal ou suas espécies" (CATÃO, 2004, p. 55).

11 “(...) não há no Brasil, seja pelo texto constitucional, seja por inspiração dos próprios entes políticos, União, Estados e Municípios, uma coordenação quanto aos incentivos fiscais, ou até mesmo uma classificação que compile, divida e qualifique os incentivos, a exemplo do que acontece nas normas do comércio internacional. Só recentemente, a Lei de Responsabilidade Fiscal veio a tratar do tema conforme comentado acima, mas mesmo assim mais voltada para a limitação dos incentivos sob uma perspectiva de gestão orçamentária do que propriamente para a sua ordenação e qualificação" (CATÃO, 2004, p. 105).

12 "Ao tempo do Estado Intervencionista, que se afirmou principalmente nas décadas seguintes ao término da 20 Grande Guerra, sob a inspiração do pensamento keynesiano, acreditava- se que as isenções e os incentivos fiscais eram a panacéia para o desenvolvimento econômico" (TORRES, 2005, p. 134).

13 "A utilização da política dos incentivos fiscais para a obtenção de determinados desideratos desejáveis aumentou consideravelmente a partir de 1964, acompanhando a formulação de novas teorias progressistas. (...)" (ELALI, 2007, p. 135).
} 


\begin{tabular}{cc}
\hline $48<\quad \begin{array}{c}\text { ROCCO ANTONIO RANGEL ROSSO NELSON } \\
\text { OS INCENTIVOS FISCAIS NO BRASIL } \\
\text { Pags. } 42-71\end{array}$ \\
\hline
\end{tabular}

Aduz o professor ELALI (2007):

Com efeito, ao tempo do Estado Intervencionista, ou mais especificamente durante as décadas de ouro do Século XX (1950 a 1970), era comum a concessão de incentivos em prol do crescimento econômico, passando o desenvolvimento econômico a ocupar o lugar de maior importância entre os princípios da economia e do díreito. Nesse contexto, Brasil, Estados Unidos e as maiores nações da Europa passaram a adotar a idéia de promover o desenvolvimento econômico através dos auxílios financeiros e fiscais. Disseminava-se, então, a idéia de que os incentivos fiscaís correspondiam à contrapartida de um interesse público, na linha do que pregavam os estudos estrangeiros (p. 115).

Na década de 70, em face dessa política de incentivos fiscais, a qual fez concessões desmedidas e imprudentes, que, frequentemente, era direcionado a setores da sociedade, constituindo verdadeiros privilégios, em afronta ao princípio da isonomia, levou o Estado provedor a uma crise financeira ${ }^{14}$. Nesse ponto merece atenção as palavras de ELALI (2007):

Naquela época, os Estados passaram a oferecer aos agentes econômicos uma série de vantagens de cunhos financeiros e fiscais, que, em verdade, constituíam o modo de fomentar as atividades econômicas.Todavia, não se ponderou com os critérios necessários o que deveria limitar a concessão de tais vantagens, levando os Estados a uma situação de grandes dificuldades em termos de déficits orçamentários. Em conseqüência, deflagrou-se uma grande crise do Estado Fiscal já nos anos 70, impondo-se uma mudança no modo de planejamento do desenvolvimento econômico e da outorga de vantagens financeiras e fiscais. (p. 122) (Grifos nossos).

SANTOS (2003), sintetiza a visão que se tinha, especificamente, dos incentivos fiscais, na época:

Ojuízo sobre os incentivos fiscais era globalmente negativo: estes, ao perturbarem o "level playing field", tenderiam a distorcer as decisões normais de investimento e, consequentemente, a produzir uma distribuição ineficiente de recursos e uma redução do bem-estar geral (p. 340).

\footnotetext{
$\overline{14}$ "O resultado de tal política foi a deflagração da grande crise do Estado Fiscal nos anos 70/80, que atingiu todos aqueles países e levou à necessidade de mudança do paradigma constitucional e econômico até então adotado. Com efeito, os países europeus e os Estados Unidos viram crescer o déficit público e se desequilibrarem as finanças locais. No Brasil o reflexo foi imediato e a política de incentivos mostrou-se perversa e nociva aos interesses da coletividade, pois não produziu o deselvolvimento econômico esperado e até gerou o desperdicio de dinheiro público" (TORRES, 2005, pp. 134-135).
} 
A partir dos novos paradigmas políticos e econômicos do neoliberalismo ${ }^{15}$, modelo do início da década de 8o, tendo como marco instituidor, em âmbito global, o chamado "Consenso de Washington", o qual refletiu os principais direcionamentos em matéria de política econômica, monetária, cambial, fiscal e comercial, a figura dos incentivos fiscais é elevada a um novo patamar, onde é associada as noções de transparência, responsabilidade ${ }^{16}$ e legitimidade ${ }^{17}$, aferindo esta quando concedida em situações de razoabilidade, levando em conta a capacidade contributiva e o desenvolvimento econômico.

Dez reformas básicas resultado deste "consenso": 1) disciplina fiscal para eliminação do déficit público; 2) mudança das prioridades em relação às despesas públicas, com a superação de subsídios; 3) reforma tributária, mediante a universalização dos contribuintes e o aumento de impostos; 4) adoção de taxas de juros positivas; 5) determinação da taxa de câmbio pelo mercado; 6) liberalização do comércio exterior; 7) extinção de restrições para os investimentos diretos; 8) privatização das empresas públicas; 9) desregulação das atividades produtivas; e 10) ampliação da segurança patrimonial, por meio do fortalecimento do direito à propriedade. (FARIA, 2004, p. 165).

\subsection{DEFINIÇÃO}

Os incentivos fiscais são conceituados, assim, pelo professor CATÃO (2004):

(...) são instrumentos de desoneração tributária, aprovados pelo próprio ente político autorizado à instituição do tributo, através de veículo legislativo específico, com o propósito de estimular o surgimento de relações jurídicas de cunho econômico. Trata-se de uma suspensão parcial ou total, mas sempre provisória, do poder que lhe é inerente, a fim de conformar determinadas situações, diferindo a tributação para o momento em que a captação de riquezas (imposição fiscal) possa ser efetuada de maneira mais efetiva, eficiente e justa (p. 13).

O professor ELALI (2007) oferta uma definição de incentivos fiscais a partir da premissa de que o mesmo é uma forma de manifestação da norma indutora tributária para

\footnotetext{
15 “(...) se afirma a partir da retomada dos fluxos privados de acumulação de capital e é progressivamente marcada pela desregulação dos mercados, pela "financeirização" do capital, pela extinção dos monopólios estatais, pela privatização de empresas públicas, pela desterritorialização da produção e por uma nova divisão social do trabalho" (FARIA, 2004, p. 111).

16 "Mas a mudança da ideologia das isenções e a revogação das concessões, facilitadas pela teoria da renúncia de receita, tomaram-se possíveis em decorrência de algumas outras idéias que passaram a predominar no campo das finanças públicas alguns anos antes. Os princípios da transparência fiscal e da responsabilidade foram relevantes para tal desiderato" (TORRES, 2005, p. 136).

17 "O art. 70 determina que o Tribunal de Contas faça o controle da legitimidade e da economicidade, o que inclui o exame do real proveito das renúncias de receita para o crescimento do País" (TORRES, 2005, p. 136).
} 
regulação econômica: “Assim, os incentivos fiscais são os instrumentos hábeis para servirem à indução econômica nas hipóteses de benefícios que passam a ser outorgados para incentivar comportamentos específicos" (p. 114).

MELO (2007), explicita sobre os incentivos fiscais tendo em vista o seu elemento teleológico:

Os incentivos fiscais consistem, basicamente, em espécie de renúncia de receitas públicas para o administrador público e benefícios aos administrados (contribuintes), objetivando o desenvolvimento econômico regional, o aumento do saldo da balança comercial, o desenvolvimento do parque industrial nacional, a geração de empregos, a colocação de produtos de fabricação nacional no mercado externo dentre outros (p. 140).

\subsection{DA EXIGÊNCIA DO ART. $165, \S^{\circ} 6^{\circ}$ DA CONSTITUIÇÃO FEDERAL}

Lembrar que por tratar de despesas e receitas públicas, todas as espécies de incentivos devem estar previstas na lei orçamentária como se determina a regra constitucional do art. 165, $\S 6^{\circ}$ da Constituição Federal ${ }^{18}$. É introjetado, por meio desse enunciado redacional, o princípio da clareza orçamentário ${ }^{19}$.

Destaca-se, que a normatividade extraída do artigo, supra, da Constituição Federal, o qual exige que o projeto de lei orçamentária contenha o demonstrativo contábil do impacto, decorrente de isenções, anistias, remissões, subsídios e benefícios de natureza financeira, tributária e creditícia, no que tange as receitas e as despesas públicas, é inspirado em pesquisas, no Estados Unidos, no qual constatou-se o uso maior de isenções (incentivos fiscais que afetam a receita), como forma de direcionar tal benefício fiscal, constituindo um verdadeiro privilégio ${ }^{20}$, em contraposição ao uso de subvenções (incentivos fiscais que afetam a despesa), pois por tratar-se de gasto público, deveria ser especificado no orçamento, e consequentemente, haveria uma maior controle e transparência.

$\mathrm{O}$ art. $165, \S 6^{\circ}$, determina que o orçamento seja acompanhado de demonstrativo dos efeitos de todas as renúncias e subvenções, desmascarando, assim, os

\footnotetext{
${ }^{18}$ Constituição Federal de 1988. Art. 165, § 60 - O projeto de lei orçamentária será acompanhado de demonstrativo regionalizado do efeito, sobre as receitas e despesas, decorrente de isenções, anistias, remissões, subsídios e benefícios de natureza financeira, tributária e creditícia.

19 "O princípio da clareza recomenda que o orçamento organize as entradas e as despesas com transparência e fidelidade. Condena as classificações tortuosas e distanciadas da técnica e os incentivos encobertos ou camuflados" (CANOTILHO, LEONCY, MENDES, SARLET, \& STRECK, 2013, p. 1762).

20 “(...) A sua existência indiscriminada tomava os sistemas fiscais mais opacos, bem como dificilmente quantificável a despesa fiscal. A sua cristalização em privilégios fiscais ou em estatutos fiscais diferenciados ameaçava conduzir a uma 'refeudalização' do sistema fiscal e a uma repartição mais injusta da carga tributária. (...)" (SANTOS, 2003, p. 340).
} 
incentivos camuflados e equiparando os privilégios radicados na receita pública (isenção, dedução, anistia, remissão, isto é, renúncias de receita ou gastos tributários) aos que operam na vertente da despesa (subvenções, restituições de tributos etc.) (TORRES, 2005, p. 136).

O professor TORRES (2005), bem especifica sobre os estudos americanos sobre a similitude, no que tange aos efeitos, entre a isenção e as subvenções:

(...) Observou Carl Shoup que, na prática americana, embora as subvenções sejam mais eficientes que as isenções (permitem o controle do cumprimento das condições impostas e o calculo do gasto público), o legislador muitas vezes opta pelas isenções porque sabe que a subvenção direta, aparecendo no orçamento, não contaria com a aprovação pública; esse comportamento e ilógico, porque a entidade que não merece a subvenção não poderá obter a isenção. No Brasil, durante muitas décadas, adotou-se a política da concessão indiscriminada de isenções e subsídios instrumentos que permitia a canalização de recursos púbicos para setores atrasados e improdutivos da economia, que não chegavam a ser conhecidos e nominados.

39. De modo que se tornou realmente importante desmascarar os diversos privilégios, a fim de que se identificassem os odiosos. O trabalho dos americanos Staley S. Surrey e Paul R. Me Daniel, ao denominar de "gasto tributário" (tax expenditure) o incentivo sediado na receita e equipará-lo ao verdadeiro gasto representado na despesa (subvenção), contribuiu decisivamente para clarear o assunto, repercutindo sobre a doutrina, a legislação e a jurisprudência de diversos países e fazendo com que o próprio orçamento dos Estados Unidos, após 1975, passasse a conter uma análise especial intitulada "Tax Expenditures", que inspirou o art. 165, § $6^{\circ}$, da CF. (...) (p. 135).

Com a finalidade que acabar com os privilégios tributários odiosos, seguindo a esteira do art. $165, \S 6^{\circ}$, o constituinte, no art. 41 dos Atos de Disposição Constitucional Transitórias, exigiu a revalidação de todos os incentivos fiscais, via instrumento legal, sob pena de revogação após dois anos da publicação da Constituição de 1988. Segue a redação ipsi literis da ADCT:

Art. 41. Os Poderes Executivos da União, dos Estados, do Distrito Federal e dos Municípios reavaliarão todos os incentivos fiscais de natureza setorial ora em vigor, propondo aos Poderes Legislativos respectivos as medidas cabíveis. $\S 1^{\mathrm{o}}$ - Considerar-se-ão revogados após dois anos, a partir da data da promulgação da Constituição, os incentivos que não forem confirmados por lei. 
$\S 2^{0}$ - A revogação não prejudicará os direitos que já tiverem sido adquiridos, àquela data, em relação a incentivos concedidos sob condição e com prazo certo. $\S 3^{\mathrm{o}}$ - Os incentivos concedidos por convênio entre Estados, celebrados nos termos do art. 23, $\S 6^{\circ}$, da Constituição de 1967, com a redação da Emenda Constitucional $\mathrm{n}^{\mathrm{o}} 1$, de 17 de outubro de 1969, também deverão ser reavaliados e reconfirmados nos prazos deste artigo.

Nessa esteira de evitar os privilégios, garantindo o controle dessas normas tributárias indutoras de forma que estejam em conformidade com os vetores axiológicos constitucionais, é o conteúdo do art. 14 da lei de responsabilidade fiscal:

Art. 14. A concessão ou ampliação de incentivo ou benefício de natureza tributária da qual decorra renúncia de receita deverá estar acompanhada de estimativa do impacto orçamentário-financeiro no exercício em que deva iniciar sua vigência e nos dois seguintes, atender ao disposto na lei de diretrizes orçamentárias e a pelo menos uma das seguintes condições:

I - demonstração pelo proponente de que a renúncia foi considerada na estimativa de receita da lei orçamentária, na forma do art. 12, e de que não afetará as metas de resultados fiscais previstas no anexo próprio da lei de diretrizes orçamentárias;

II - estar acompanhada de medidas de compensação, no período mencionado no caput, por meio do aumento de receita, proveniente da elevação de alíquotas, ampliação da base de cálculo, majoração ou criação de tributo ou contribuição (Grifos nossos).

\section{Assevera o professor OLIVEIRA (2010):}

A renúncia de receita é providência política que gera crescente rivalidade entre Municípios e entre Estados, os quais abrem mão de parte da receita do ICMS, redundando em confrontos inconvenientes. A LC 101/2000 veio dar grande passo na limitação de possíveis conflitos. A renúncia de receita, através de concessão ou ampliação de incentivo ou benefício de natureza tributária, deve estar acompanhada de estimativa do impacto orçamentário-financeiro no exercício em que deva iniciar sua vigência (p. 134) ${ }^{21}$.

Afere-se que a preocupação do constituinte em evitar o desvirtuamento dos incentivos fiscais foi tamanha que a aplicação de subvenções e renúncias de receitas sofrem fiscalização pelo Tribunal de Contas, como determina o art. 70 da Constituição ${ }^{22}$. Além disso, o $§ 6^{\circ}$ do art. 150 
do texto constitucional, exige que a concessão de qualquer subsídio ou isenção, redução de base de cálculo, concessão de crédito presumido, anistia ou remissão, seja feito por meio de lei específica ${ }^{23}$.

Arrebata o professor CARRAZZA (2013): "Frisamos que, exceção feita aos casos de imunidade (previstos na própria Constituição), os incentivos fiscais que se traduzem em mitigações ou supressões da carga tributária só são válidos se, observados os limites constitucionais, (...)” (p.703).

Nesse interim, constata-se que os incentivos fiscais devem respaldo ao plexo normativo fruto dos principios constitucionais, como o do princípio da legalidade, princípio da isonomia, princípio federativo, princípio da segurança jurídica, princípio da uniformidade tributária, dentre outros.

\subsection{ESPÉCIES}

Os incentivos fiscais podem ocorrer sobre as despesas e sobres as receitas públicas. A partir dessas duas facetas, da matéria financeira, será anotado os incentivos fiscais, quanto as suas espécies.

É salutar destacar que os incentivos, seja sobre as despesas, seja sobre a receita, são fenômenos relacionados, podendo se dizer que são "as faces da mesma moeda", constituindo-se diferenças apenas no aspecto formal, doravante, a consequência financeira será a mesma ${ }^{24}$.

Em outras palavras, receita e despesa são duas facetas de uma mesma questão, impondo-se que haja um controle rigoroso na concessão de qualquer das formas de auxílio estatal, seja porque se está falando de recursos públicos, seja porque não se pode afastar da busca da eficiência econômica que deve gerir as políticas públicas (...) (ELALI, 2007, p. 120).

(...) Hoje prevalece na temática dos privilégios fiscais o conceito de renúncia de

\footnotetext{
21 "Todas as formas de renúncia de receita levam a odiosas situações, normalmente em prejuízo do erário. Objetivam, evidentemente, melhoria das condições locais. No entanto, as medidas são feitas de forma atrabiliária e sem qualquer fundamento legal. Basta a elas o cunho político irresponsável. Agora, a lei corta quaisquer tentativas de benefício indevido, em detrimento de outro ente federativo ou mesmo em detrimento da União ou do Estado, que, ao final, irá suportar a renúncia mediante repasse de seus recursos" (OLIVEIRA, 2010, p. 134).

${ }^{22}$ Constituição Federal. Art. 70. A fiscalização contábil, financeira, orçamentária, operacional e patrimonial da União e das entidades da administração direta e indireta, quanto à legalidade, legitimidade, economicidade, aplicação das subvenções e renúncia de receitas, será exercida pelo Congresso Nacional, mediante controle externo, e pelo sistema de controle interno de cada Poder.

${ }^{23}$ Constituição Federal. Art. 150. §6. Qualquer subsídio ou isenção, redução de base de cálculo, concessão de crédito presumido, anistia ou remissão, relativos a impostos, taxas ou contribuições, só poderá ser concedido mediante lei específica, federal, estadual ou municipal, que regule exclusivamente as matérias acima enumeradas ou o correspondente tributo ou contribuição, sem prejuízo do disposto no art. 155, § 2.ㅇ, XII, g. (Redação dada pela Emenda Constitucional no 3, de 1993).

24 "Os privilégios tributários, que operam na vertente da receita, estão em simetria e podem ser convertidos em privilégios financeiros, a gravar a despesa pública. A diferença entre elas é apenas jurídico-formal. A verdade é que a receita e a despesa são entes de relação, existindo cada qual em função do outro, donde resulta que tanto faz diminuir-se a receita, pela isenção ou dedução, como aumentar-se a despesa, pela restituição ou subvenção, que a mesma consequência financeira será obtida". (CANOTILHO, LEONCY, MENDES, SARLET, \& STRECK, 2013, p. 1762)
} 
receita, que aparece no art. 70 da CF/88 e no art. 14 da Lei de Responsabilidade Fiscal, significandu que todos os instrumentos tributários que operam na vertente da receita produzem o mesmo efeito econômico dos itens da despesa (restituição de tributos, subvenção, subsídio), isto é, o enriquecimento do contribuinte e o empobrecimento do Estado." O conceito de renúncia de receita surgiu na literatura jurídico-financeira justamente para realçar a similitude entre os efeitos econômicos das isenções e demais incentivos fiscais e das subvenções, (...) (TORRES, 2005, p. 132).

\subsubsection{DOS INCENTIVOS FISCAIS SOBRE AS DESPESAS PÚBLICAS}

No que se refere aos incentivos fiscais, sobre as despesas, podem ser na modalidade de subvenção, créditos presumidos e subsídios.

\subsubsection{SUBVENÇÃO}

Seria uma forma de doação condiciona pela entidade de direito público, onde a entidade privada necessitaria ofertar uma contraprestação pelo benefício recebido.

Tal incentivo é regido pelas normas de direito financeiro: "Quanto à natureza jurídica, poderia se afirmar, $a b$ initio, se tratar de incentivo financeiro ou creditício para finalidade espedfica, regido pelas normas do Direito Financeiro. (...)" (CATÃO, 2004, p. 60) ${ }^{25}$.

Essa modalidade de incentivo fiscal possui duas formatações: subvenção de custeio e subvenção de investimento.

$\mathrm{Na}$ de custeio é ofertado um aporte financeiro para estimular certa atividade, a qual sem esse incentivo, em condições regulares não seria galgado. No caso da subvenção de investimento, a entidade pública faz a transferência de capital para a entidade privada para que a mesma preste certa atividade específica.

A lei geral que estatui as normas de direito financeiro (Lei $n^{0} 4.320 / 64$ ), assim distingue as subvenções:

Art. 12....

$\S 3^{\mathrm{O}}$ Consideram-se subvenções, para os efeitos desta lei, as transferências destinadas a cobrir despesas de custeio das entidades beneficiadas, distinguindose como:

I - subvenções sociais, as que se destinem a instituições públicas ou privadas de caráter assistencial ou cultural, sem finalidade lucrativa;

25 “(...) as subvenções, que constituem um benefício de natureza financeira (...)” (ELALI, 2007, p. 48). 
II - subvenções econômicas, as que se destinem a empresas públicas ou privadas de caráter industrial, comercial, agrícola ou pastoril (Grifos nossos).

As subvenções sociais, visaria "a prestação de serviços essenciais de assistência social, médica e educacional, sempre que a suplementação de recursos de origem privada aplicados a esses objetivos, revelar-se mais econômica" ${ }^{26}$.

Já as subvenções econômicas dariam "cobertura dos déficits de manutenção das empresas públicas, de natureza autárquica ou não, far-se-á mediante subvenções econômicas expressamente incluídas nas despesas correntes do orçamento da União, do Estado, do Município ou do Distrito Federal” ${ }^{27}$, bem como seriam dotações orçamentárias possíveis de destinar cobrir "a diferença entre os preços de mercado e os preços de revenda, pelo Governo, de gêneros alimentícios ou outros materiais" e ao "pagamento de bonificações a produtores de determinados gêneros ou materiais" ${ }^{28}$.

Essas modalidades de subvenções compõe os elementos da transferência corrente ${ }^{29}$, essa integrante da categoria econômica de despesa corrente ${ }^{30}$.

\subsubsection{CRÉDITOS PRESUMIDOS}

A desoneração, no que tange aos créditos presumidos, seria a presunção do recolhimento de um tributo (este que de fato não ocorreu) o qual se constituirá quando venha por beneficiar o contribuinte, ou seja, quando a presunção legal constitua-se em um valor menor do que o valor real (SILVA \& MOTTA FILHO, 2010). É um incentivo cuja natureza varia com a normatividade dada em lei, fazendo as vezes de isenção, subvenção ou mera redução da base de cálculo (ELALI, 2007).

Afira-se o caso do crédito presumido, para o IPI, previsto na Lei ${ }^{\circ} 9.363 / 96$, que tem por finalidade favorecer a exportação de mercadorias de fabrico nacional, a partir de insumos adquiridos no mercado interno.

O art. $153, \S 3^{\circ}$, III da Constituição Federal $^{31}$ determinara a regra imunizante do IPI, no que tange aos produtos industrializados para exportação. Todavia, apresente imunidade não se aplica as contribuições especiais do PIS/PASEP e CONFINS.

De tal sorte, com a finalidade de favorecer a exportação, permitindo um preço do

\footnotetext{
${ }^{26}$ Art. 16 da Lei no $4.320 / 64$.

${ }^{27}$ Art. 18 da Lei no $4.320 / 64$

${ }^{28}$ Art. 18, parágrafo único da Lei no 4.320/64.

${ }^{29}$ Lei no 4.320/64. Art. 12. § 20 Classificam-se como Transferências Correntes as dotações para despesas as quais não corresponda contraprestação direta em bens ou serviços, inclusive para contribuições e subvenções destinadas a atender à manifestação de outras entidades de direito público ou privado.

${ }^{30}$ Art. 13 da Lei $n$ ㅇ 4.320/64.
} 
produto mais competitivo no cenário internacional, a Lei $n^{0}$ 9.363/96 cria o crédito presumido, que ressarcirá as empresas exportadoras, em relação aos valores pagos a título de PIS/PASEP e CONFINS incidentes sobre as respectivas aquisições, no mercado interno, de matérias-primas, produtos intermediários e material de embalagem, para utilização no processo produtivo.

\subsubsection{SUBSÍDIOS}

Seria a intervenção estatal na economia de forma a alavancar ou incentivar a produção industrial de certos seguimentos, ou mesmo protege-lo de certa instabilidade econômica ${ }^{32}$. Os subsídios visam a equalização de preços, evitando ou minorando as distorções do mercado ou como forma de promoção do desenvolvimento, com o fito de redução das desigualdades sociais.

Percebe-se que os subsídios atuariam na dimensão macroeconômica.

Sobre a conceituação de subsídios, assim explicita o professor PIRES (2001):

(...) toda ajuda oficial de governo, com o fim deestimular a produtidade de indústrias instaladas no páís. O subsidio ter por objetivo promover o desenvolvlmtinto de setores estratégicos sob o ponto de vista econômico, ou de regiões mais atrasadas, além de servir como instrumento de incentivo às exportações, sobretudo em paises em desenvolvimento (p. 36).

No que tange, ainda aos subsídios, segue a advertências sobre o seu uso:

A concessão de subsídios para o fomento da atividade econômica deve ser utilizada com parcimônia, na medida do possível para promover o desenvolvimento sustentável e não causar discriminação. Por tais preocupações e em especial para repudiar subsídios que possam ocasionar danos à economia de outros países, a concessão deles condiciona-se a diretrizes internacionais (ESTIGARA, PEREIRA, \& LEWIS, 2009, p. 85) ${ }^{33}$ (Grifos nossos).

\footnotetext{
${ }^{31}$ Constituição Federal. Art. 153. Compete à União instituir impostos sobre: ... § 3ㅇ - O imposto previsto no inciso IV: ...

III - não incidirá sobre produtos industrializados destinados ao exterior.

32 “(...) podem ser estímulos de natureza fiscal ou comercial, para promover determinadas atividades econômicas por períodos transitórios (...)” (ELALI, 2007, p. 48). “...se a norma tributária indutora caracterizar uma vantagem e constatado seja a vantagem especifica a uma empresa ou indústria, ou grupo de indústrias, fica apontado um subsídio. (...)” (SCHOUERI, 2005, p. 213).

${ }_{33}$ "Nesse sentido, o Acordo Geral sobre Tarifas e Comércio (GATT) admite subsídios, para, dentre outras razões, eliminar desvantagens industriais, econômicas e sociais de regiões específicas, facilitar a reestruturação de certos setores, sustentar o nível de emprego, encorajar programas de pesquisa e desenvolvimento e para a promoção de políticas públicas e para implementar programas e políticas econômicas destinadas a promover o desenvolvimento econômico e social de países em desenvolvimento (...)" (ESTIGARA, PEREIRA, \& LEWIS, 2009, p. 85).
} 


\subsubsection{DOS INCENTIVOS FISCAIS SOBRE AS RECEITAS PÚBLICAS}

Já em relação aos incentivos fiscais sobre as receitas, esta podem ocorrer na modalidade de isenção, diferimentos, remissão e anistia.

O professor Marcos Catão constata que os operadores do direito (legislador, doutrina e tribunais) dedicaram-se um maior estudo em relação aos incentivos fiscais decorrente das receitas públicas. Em face disse, afere-se uma expansão sobre os incentivos nas modalidades isenção e anistia, cuja eficácia ficaram a desejar (CATÃO, 2004).

\subsubsection{ISENÇÃO ${ }^{34}$}

Esta seria uma forma de exclusão do crédito tributário, previsto no art. 175, I, do Código Tributário Nacional, o qual tem seu fundamento na falta de capacidade econômica do sujeito passivo ou em vista de atingir objetivos de utilidade geral ou de oportunidade política (CARRAZZA, 2013).

Aduz CARRAZZA (2013) sobre o pressuposto legitimador das isenções:

Também as isenções tributárias só podem ser concedidas quando, ao mesmo tempo em que favorecem pessoas, têm em conta objetivos constitucionalmente consagrados (proteção à velhice, à família, à cultura, aos que apresentam desenvolvimento mental precário, aos economicamente mais fracos, isto é, que revelam ausência de capacidade econômica para suportar o encargo fiscal, e assim avante) (p. 986).

No que tange a natureza jurídica da isenção, na esteira da doutrina clássica, seria uma espécie de dispensa de pagamento de tributo, cuja normatividade é veiculada por dispositivo legal, sendo defendida pelo professor Rubens Gomes de Sousa e Amílcar de Araújo Falcão.

Clássica é a tese de que a isenção é um favor legal consubstanciado na dispensa do pagamento do tributo devido. Sensível a reclamos de ordem ética, social, econômica, Política, financeira etc., a autoridade legislativa desonera o sujeito Passivo da obrigação tributária de cumprir o dever jurídico de recolher o gravame, mediante dispositivo expresso de lei. Toma-se como premissa que o fato jurídico ocorre,

\footnotetext{
34 "A isenção, de outro lado, pressupõe a incidência da norma tributária impositiva. Não incidisse, não surgiria qualquer obrigação, não havendo a necessidade de lei para a exclusão do crédito. A norma de isenção sobrevém justamente porque tem o legislador a intenção de afastar os efeitos da incidência da norma impositiva que, de outro modo, implicaria a obrigação de pagamento do tributo" (PAULSEN, 2014, p. 228).
} 


\begin{tabular}{cc}
\hline $58<\quad \begin{array}{c}\text { ROCCO ANTONIO RANGEL ROSSO NELSON } \\
\text { OS INCENTIVOS FISCAIS NO BRASIL } \\
\text { Pags. } 42-71\end{array}$ \\
\hline
\end{tabular}

nominalmente, nascendo o vínculo obrigacional. Por força da norma isentante; opera-se a dispensa do débito tributário. Essa posição doutrinaria teve em Rubens Gomes de Sousa (o principal co-autor do Anteprojeto do Código Tributário Nacional) seu grande patrono e, ainda que não tenha sido plasmada no texto, impregnou toda a disciplina jurídica da matéria naquele Estatuto (CARVALHO, 2009, p. 522).

Ou seja, ocorre o fato gerador, dando ensejo ao surgimento da obrigação tributária, todavia, sucede a dispensa, via lei, do pagamento do tributo.

Para a doutrina tributarista moderna, tendo como arautos Alfredo Augusto Becker e Souto Maior Borges, a isenção, veiculado por lei, suspenderia a eficácia da lei constituidora do tributo, de sorte que não havendo a incidência do fato gerador, não ocorreria a formação da obrigação tributária, ou seja, para essa linha de pensamento a isenção seria uma hipótese de não-incidência legalmente qualificada (CARRAZZA, 2013).

A realização da hipótese de incidência da regra jurídica de isenção, faz com que esta regra jurídica incida justamente para negar a existência de relação jurídica tributária. Por sua vez as hipóteses não enquadráveis dentro da hipótese de incidência da regra jurídica explícita de isenção tributária são precisamente as hipóteses de incidência de regras jurídicas implícitas de tributação (BECHER, 2007, p. 325).

No que tange a dimensão de estudo do presente artigo, restringir-se-á a matéria sobre a natureza da isenção as duas teorias explicitadas. Todavia, não se desconhece ou ignora o fato de ser uma matéria cadente, longe de um de um consenso, cujo estudo gerou diversas teorias, como a da isenção como fato impeditivo: “... isenção como delimitação negativa da hipótese de incidência tributária; como tutela jurídica do interesse do contribuinte como limitação ao poder de tributar; como renúncia ao exercício da competência tributária etc" (CARVALHO, 2009, p. 995) ${ }^{35}$.

Anota CARRAZZA (2013) sobre essa teoria: "Positivamente, soa absurdo que a lei tributária que concede uma isenção dispense o pagamento do tributo. Afinal, a lei de isenção é logicamente anterior à ocorrência do fato que, se ela não existisse, aí, sim seria imponível” (p. 991).

As consequências jurídicas de entender a isenção como dispensa de pagamento ou como uma forma de não-incidência tributária está nos efeitos da revogação da lei isentiva. Para a doutrina clássica a cobrança do tributo poderia ser feita imediatamente a revogação da lei instituidora da isenção; para a segunda corrente a lei revogadora constituiria uma nova incidência tributária, de tal forma que deveria obedecer os ditames do princípio da anterioridade tributária, devendo ser cobrado no ano fiscal subsequente (PIRES, 2007). 
Nas palavras do professor CARVALHO (2009): “o mecanismo das isenções é um forte instrumento de extrafiscalidade" (p. 535) ${ }^{36}$.

“(...) O afastamento da carga tributária, no caso da isenção, se faz por razões estranhas a normal estrutura que o ordenamento legal imprime ao tributo seja em atenção a capacidade contributiva, seja por razões de cunho extrafiscal” (PAULSEN, 2014, p. 228).

\subsubsection{DIFERIMENTOS}

O diferimento seria uma alteração do aspecto temporal do fato gerador, onde alongar-seia o prazo para o adimplemento da obrigação tributária ${ }^{37}$. Não há um consenso quanto a sua natureza jurídica ${ }^{38}$.

Os professores SILVA E MOTTA FILHO (2010) apontam como o surgimento dessa modalidade desonerativas, no Brasil, através do Ato Complementar $n^{\circ} 31$ de 1966:

O surgimento desse fenômeno desonerativo teve origem com o advento do Ato Complementar n. 31, de 28-12-1963, em decorrência da modificação da sistemática de cobrança do então ICM pertencente aos Municípios, preconizada pela Carta Constitucional de 1967 (p. 333).

O professor MELO (2012), bem conceitua e contextualiza a prática do diferimento:

Constitui uma técnica impositiva de deslocamento da exigência do tributo para momento posterior à ocorrência do originário fato gerador, com a imputação da responsabilidade de seu recolhimento a terceiro.

É utilizado para operações de pequeno porte, ou realizadas por contribuintes sem estrutura empresarial, de proporções modestas ou mesmo sem um efetivo estabelecimento, obetivando a simplificação fiscal de determinadas operações.

Diversas atividades vêm sendo enquadradas nesta sistemática como, por exemplo, as relativas às seguintes mercadorias: algodão em caroço, café cru, cana-deaçúcar em caule, feijão, mamona, soja, produtos in natura, semente, insumos

\footnotetext{
36 “(...) Dosando equilibradamente a carga tributária, a autoridade legislativa enfrenta as situações mais agudas, onde vicissitudes da natureza ou problemas econômicos e sociais fizeram quase que desaparecer a capacidade contributiva de certo segmento geográfico ou social. A par disso, fomenta as grandes iniciativas de interesse público e incrementa a produção, o comércio e o consumo, manejando de modo adequado o recurso jurídico das isenções. (...) (CARVALHO, 2009, p. 535).

37 "Assim, na verdade, o diferimento nada mais é do que a dilação do pagamento do imposto e atinge o aspecto temporal do fato gerador, tendo em vista que a sua ocorrência é postergada no tempo, realizando-se num momento futuro" (SILVA \& MOTTA FILHO, 2010, p. 333). “(...) que representa uma isenção condicionada, na linguagem usada, dentre outros, por Roque Antônio Carrazza" (ELALI, 2007, p. 49).

38 “Ora é aceito como uma não incidência, ora como moratória e, às vezes, ainda, como isenção” (SILVA \& MOTTA FILHO, 2010, p. 333).
} 


\begin{tabular}{cc}
\hline $60<\quad \begin{array}{c}\text { ROCCO ANTONIO RANGEL ROSSO NELSON } \\
\text { OS INCENTIVOS FISCAIS NO BRASIL } \\
\text { Pags. } 42-71\end{array}$ \\
\hline
\end{tabular}

agropecuários, coelho, gado em pé, eqüino de raça, subprodutos da matança do gado, leite, pescado, resíduos de materiais, metal não ferroso, componentes de processamento de dados.

Usualmente, o ICMS fica diferido para operações posteriores como remessa para outro Estado, exportação, industrialização etc. (p. 336).

\subsubsection{REMISSÃO E ANISTIA}

A remissão constitui modalidade de extinção do crédito tributário, segundo o art. 156, IV do Código Tributário Nacional, onde a administração fazendária, em face de uma liberalidade, desobriga o sujeito passivo quanto adimplemento do crédito tributário. Seria, nada mais do que "perdão legal de créditos tributários" (SILVA \& MOTTA FILHO, 2010, p. 326), previsto em lei, sob os auspícios dos fundamentos desenhados no art. 172 do Código Tributário Nacional:

Art. 172. A lei pode autorizar a autoridade administrativa a conceder, por despacho fundamentado, remissão total ou parcial do crédito tributário, atendendo:

I - à situação econômica do sujeito passivo;

II - ao erro ou ignorância excusáveis do sujeito passivo, quanto a matéria de fato;

III - à diminuta importância do crédito tributário;

IV - a considerações de eqüidade, em relação com as características pessoais ou materiais do caso;

V - a condições peculiares a determinada região do território da entidade tributante.

A isenção e a remissão geram os mesmos efeitos, o não recolhimento do tributo, todavia, não se confundem. O primeiro "impede que o tributo nasça e a remissão faz desaparecer o tributo já nascido" (CARRAZZA, 2013, p. 1039) ${ }^{39}$.

(...) a caracterização das isenções como dispensa legal do pagamento de tributo devido induz à confusão entre isenção e remissão de débitos, porque a distinção entre ambas reside precisamente na circunstância de que, enquanto a lei de isenção impede $a$ priori o nascimento do débito, configurando hipótese de nãoincidência por não haver-se realizado concretamente o fato gerador da tributação, a lei de remissão de débito tributário dispensa o pagamento de tributo, devido pela efetiva realização concreta do fato gerador da tributação. A remissão de débito tributário não impede o surgimento do fato gerador, posto que decorre de ato legislativo editado a posteriori (...) (BORGES, 2011, p. 211).

$\overline{39 ~ “(. . .) ~ a ~ l e i ~ d e ~ i s e n c ̧ a ̃ o ~ e ́ ~ u m ~ p r i u s ~ e ~ a ~ l e i ~ r e m i s s i v a ~ u m ~ p o s t e r i u s, ~ n o ~ q u e ~ r e f e r e ~ a o ~ n a s c i m e n t o ~ d o ~ t r i b u t o ” ~(C A R R A Z Z A, ~ 2013, ~ p . ~}$ 1039). 
Já a anistia seria a segunda forma de exclusão do crédito tributário, nos termos do art. 175, II, do Código Tributário Nacional, onde o sujeito ativo da obrigação tributária perdoaria o sujeito passivo, total ou parcialmente, no que tange as infrações tributárias ${ }^{40}$.

A anistia dar-se-á via lei, não abrangendo certas infrações tributárias, como determina o art. 180 do Código Tributário Nacional:

Art. 180. A anistia abrange exclusivamente as infrações cometidas anteriormente à vigência da lei que a concede, não se aplicando:

I - aos atos qualificados em lei como crimes ou contravenções e aos que, mesmo sem essa qualificação, sejam praticados com dolo, fraude ou simulação pelo sujeito passivo ou por terceiro em benefício daquele;

II - salvo disposição em contrário, às infrações resultantes de conluio entre duas ou mais pessoas naturais ou jurídicas.

Atente-se ao fato de que pela sua própria natureza de exclusão de crédito tributário, estar a falar de uma infração tributária que constituiu-se em obrigação tributária, todavia, não fora lançado. Não pode anistiar multa tributária já lançada.

Por fim, apesar da semelhança (ambos tratam de perdão), o instituto da anistia não se confunde com o da remissão ${ }^{41}$. Como arremata CARVALHO (2009) sobre o assunto:

(...) Ao remitir, o legislador tributário perdoa o débito do tributo, abrindo mão do seu direito subjetivo de percebê-lo; ao anistiar, todavia, a desculpa recai sobre o ato da infração ou sobre a penalidade que lhe foi aplicada. Ambas retroagem, operando em relações jurídicas já constituídas, porém de índoles diversas: a remissão, em vínculos obrigacionais de natureza estritamente tributária; a anistia, igualmente em liames de obrigação. mas de cunho sancionatório. E, além disso, a anistia pode revelar o esquecinzento da infração que fez irromper a medida punitiva, enquanto a remissão nunca incide no fato jurídico tributário, desconstituindo-o ou apagando-o pelo esquecimento expresso. Têm um ponto comum: as duas figuras encerram o perdão (...) (p. 539).

\footnotetext{
40 "Importante ressaltar que, ao se enfocar a anistia, normalmente a explicação se dá pelo seu efeito, ou seja, exclusão da penalidade pecuniária. Entretanto, ao apreciarmos o dispositivo legal, vamos constatar que a exclusão atinge diretamente a infração cometida e não a multa consequente. Expliquemos: em não sendo mais determinado ato considerado infração, ou seja, ilícito tributário, não há razão de ser aplicada a respectiva sanção" (SILVA \& MOTTA FILHO, 2010, p. 324).

41 "Anistia é o perdão das infrações à legislação tributária e das respectivas sanções. Não atingi o tributo em si, que persiste. O perdão do tributo ocorre através da remissão, nos termos do art. 172 do CTN" (PAULSEN, 2007, p. 1135). "A anistia se dá quando o legislador exclui o crédito tributário decorrente de infrações a legislação tributária (art. 180 d0 CTN), dispensando o pagamento da multa. Não se confunde com a remissão, ou seja, com a extinção do crédito que alcança o próprio tributo devido (art. 172 do CTN)" (PAULSEN, 2014, p. 229).
} 


\subsection{INCENTIVOS FISCAIS NO FOMENTO DE DIVERSAS NORMAS-PROGRAMAS CONSTITUCIONAIS}

\subsubsection{PROMOÇÃO DA CULTURA}

No art. 215 da Constituição Federal extrai-se as normas programáticas relativas ao direito a cultura, este um direito fundamental, prescrevendo que "o Estado garantirá a todos o pleno exercício dos direitos culturais e acesso às fontes da cultura nacional, e apoiará e incentivará a valorização e a difusão das manifestações culturais" (Grifos nossos).

A cultura e os direitos culturais são na sistemática constitucional brasileira, direitos fundamentais, individuais e sociais, neste sentido gozam da perenidade que lhes empresta à cláusula de vedação contida no inciso III do art. 60 da CF. A expressão cultura utilizada pelo constituinte de 1988 tem endereço certo; dirigindo imediatamente a significação das capacidades do fazer humano e todas as suas manifestações, espirituais, artísticas, intelectuais e científicas, bem como a formatação de uma subconstituição cultural, que pode inclusive caracterizar um Estado de Cultura, onde a expressão máxima está vinculada ao acervo comum da identidade de cada um dos grupos que coopera para a identidade nacional, desde suas memórias históricas, condições étnicas, produção artística, intelectual, filosófica e sociológica. Os princípios de interpretação do sintagma cultura protegida não está divorciada da intenção do constituinte impressa no preâmbulo constitucional, e especialmente do programa que desenhou o art. $3^{\mathrm{o}}$, I, pois uma sociedade justa livre e solidária é uma sociedade mediada pela cultura, portanto, é neste sentido que os direitos culturais são direitos humanos e são direitos fundamentais sociais, sendo que o amplo e complexo conjunto de suas manifestações conforma os fundamentos da nacionalidade (Grifos nossos)

(CANOTILHO, LEONCY, MENDES, SARLET, \& STRECK, 2013, p. 1982).

As diretrizes constitucionais sobre a cultura enunciam, em seu $\S 6^{\circ}$ do art. 215, que a lei criará um "Plano Nacional de Cultura, de duração plurianual, visando ao desenvolvimento cultural do País e à integração das ações do poder público", o qual, dentre várias finalidades elencadas, destaca-se a "produção, promoção e difusão de bens culturais".

Não só isso, o $\$ 3^{\circ}$ do citado artigo, preceitua, expressamente, a criação de incentivos "à produção e conhecimentos de bens e valores culturais", via dispositivo legal. Afere-se de forma palmar a figura do incentivo fiscal para fins de promoção da cultura, no Brasil, o qual deu-se via Lei $n^{0} 8.313 / 91$, conhecida como lei Rouanet, bem como pela Lei $n^{0} 8.685 / 93$, que cria meios de incentivos a atividade audiovisual.

É sabido que anterior a Constituição Federal de 1988, fora criado a Lei ${ }^{0} 7 \cdot 505 / 86$, a qual obteve a alcunha de lei Sarney, a qual trata sobre benefícios fiscais na área do imposto de 
renda concedidos a operações de caráter cultural ou artístico, ainda estando em vigor.

A título de exemplo, destaca-se que lei Rouanet cria o Programa Nacional de Apoio à Cultura (Pronac), o qual tem por finalidade:

I - contribuir para facilitar, a todos, os meios para o livre acesso às fontes da cultura e o pleno exercício dos direitos culturais;

II - promover e estimular a regionalização da produção cultural e artística brasileira, com valorização de recursos humanos e conteúdos locais;

III - apoiar, valorizar e difundir o conjunto das manifestações culturais e seus respectivos criadores;

IV - proteger as expressões culturais dos grupos formadores da sociedade brasileira e responsáveis pelo pluralismo da cultura nacional;

V - salvaguardar a sobrevivência e o florescimento dos modos de criar, fazer e viver da sociedade brasileira;

VI - preservar os bens materiais e imateriais do patrimônio cultural e histórico brasileiro;

VII - desenvolver a consciência internacional e o respeito aos valores culturais de outros povos ou nações;

VIII - estimular a produção e difusão de bens culturais de valor universal, formadores e informadores de conhecimento, cultura e memória;

IX - priorizar o produto cultural originário do País ${ }^{42}$.

Para a consecução dessas finalidades facultou-se que às pessoas físicas ou jurídicas a opção pela aplicação de parcelas do Imposto sobre a Renda, a título de doações ou patrocínios, tanto no apoio direto a projetos culturais apresentados por pessoas físicas ou por pessoas jurídicas de natureza cultural, como através de contribuições ao Fundo Nacional da Cultura (FNC) ${ }^{43}$.

No art. 26 da Lei $n^{0}$ 8.313/91, trata dos percentuais dedutíveis no caso de doação e patrocínio pela pessoa física e jurídica:

Art. 26. O doador ou patrocinador poderá deduzir do imposto devido na declaração do Imposto sobre a Renda os valores efetivamente contribuídos em favor de projetos culturais aprovados de acordo com os dispositivos desta Lei, tendo como base os seguintes percentuais:

I - no caso das pessoas físicas, oitenta por cento das doações e sessenta por cento dos patrocínios; 
II - no caso das pessoas jurídicas tributadas com base no lucro real, quarenta por cento das doações e trinta por cento dos patrocínios.

$\S 10$ A pessoa jurídica tributada com base no lucro real poderá abater as doações e patrocínios como despesa operacional.

§ 20 O valor máximo das deduções de que trata o caput deste artigo será fixado anualmente pelo Presidente da República, com base em um percentual da renda tributável das pessoas físicas e do imposto devido por pessoas jurídicas tributadas com base no lucro real (Grifos nossos).

\subsubsection{FOMENTO DO DESENVOLVIMENTO TECNOLÓGICO E CIENTÍFICO}

A matéria de ciência e tecnologia fora contemplada na carta cidadão de 1988, no art. 218, onde determina que "o Estado promoverá e incentivará o desenvolvimento científico, a pesquisa e a capacitação tecnológicas”.

Semelhante ao direito da cultura, a promoção da ciência e da tecnologia é direito fundamental, por tratar-se de um elemento formador da personalidade do indivíduo, sendo fulcral, não só para a expansão do Estado como para a sociedade.

É nesses termos as palavras da professora MARQUES (2013), feita em obra coletiva, comentando os artigos da Constituição:

Os arts. 218 e 219, em conjunto com as outras normas constitucionais, regulam estes "direitos sociais", direitos fundamentais, formando todos o conceito jurídico constitucional de Ciência no Brasil. Neste Capítulo IV, são traçadas as linhas mestras e valores (opção-decisão), que deverão reger a ciência e a tecnologia, sua força normativa (Hesse, 1991, p. 1) e eficácia horizontal (Drittwirkung) no direito privado. Na ADI 3.510, o Supremo Tribunal Federal destacou esta visão unitária da Constituiçâo de 1988, realçando a dignidade da pessoa humana, o princípio da liberdade da ciência e seus limites, a impordncia da ciência e da tecnologia para os indivíduos, a sociedade e não só o Estado. Em outras palavras, a Constituição de 1988, quando regula a.educação, cultura, ciência e tecnologia na ordem social, esclarece que, no desenvolvimento pleno da personalidade a ciência é hoje parte essencial: ciência faz parte da personalidade, do homo faber, na expressão famosa de Hannah Arendt, o homem criativo e trabalhador da ordem social (e cultural); ciência (e tecnologia) faz parte da personalidade do homo economicus, desde a visão de Adaro Smith (Mastetten, p. 268e s.), aquele que atua no mercado, que consome, que se define pela informação, produtbs e conhecimento que detêm, como parte de sua esfera de poder, do patrimônio pessoal do cidadão-consumidor (ordem econômica) (p. 1993). 
No $\S 4^{\circ}$ do art. 218 da Constituição, encarrega a lei de fomentar o investimento pelas empresas "em pesquisa, criação de tecnologia adequada ao País, formação e aperfeiçoamento de seus recursos humanos (...)".

O dispositivo constitucional, supra explicitado, é criticado, posto que essa norma programática seria uma maneira típica do Estado em se desobrigar na promoção do desenvolvimento tecnológico e científico, não onerando de forma significativa o orçamento ${ }^{44}$.

Em decorrência dessa norma programática fora constituído a Lei $\mathrm{n}^{0} 11.196 / 05^{45}$, o qual vem por constituir regras sobre incentivos fiscais para a inovação tecnológica.

Antes de analisar o conteúdo do disposto legal supra, é importante aferir o conjunto normativo anterior que incentiva a pesquisa tecnológica, nos termos explicitados pelo professor SCHOUERI (2005):

(...) tecnológica, já em 1988, por meio do Decreto-Lei ${ }^{0}{ }^{2.433}$, que criou incentivos específicos para estimular o desenvolvimento tecnológico, conhecido como "Nova Política Industrial”, adotando-se, junto com os incentivos fiscais, medidas voltadas à redução de barreiras não-tarifárias, à desregulamentação da concorrência interna: e à eliminação de entraves ao capital estrangeiro. Em 1991, a Lei n ${ }^{\circ} 8.248$ dispunha sobre a capacitação e competitividade do setor de informática c automação, o que foi alargado por meio da Lei $\mathrm{n}^{0}$ 8.661, em 1993, para outros setores, ao se introduzirem incentivos fiscais para a capacitação tecnológica da indústria e da agropecuária. Em síntese, a última lei previa: i) dedução; do próprio imposto devido, até o limite de oito por cento, do valor gasto $\mathrm{cm}$ pesquisa c desenvolvimento, além de sua dedução como despesa, podendo o excesso do crédito ser transferido a períodos subsequentes; ii) isenção do Imposto sobre Produtos Industrializados sobre equipamentos, máquinas, aparelhos e instrumentos aplicados em pesquisa e desenvolvimento; iii) depreciação acelerada do custo das referidas máquinas; iv) amortização acelerada dos bens intangíveis voltados à pesquisa; v) redução do imposto de renda sobre remessas ao exterior a título de royalties e assistência; vi) ampliação do limite de dedução dos pagamentos a título de royalties, para até dez por cento da receita liquida das vendas dos bens produzidos com a tecnologia assim desenvolvida (p. 124) (Grifos nossos).

\footnotetext{
44 "É a típica forma do Estado liberal. Desta forma, com o incentivo à livre-iniciativa, através dos estímulos fiscais, como as isenções, a concepção de créditos e outros benefícios, encontrou no Estado uma forma a mais de desobrigar-se para com o desenvolvimento do conhecimento científico e tecnológico, o que significa redução dos encargos financeiros (...)" (PAULA, 2004, p. 275).

${ }^{45}$ Lei regulamentada pelo Decreto № 5.563/05.
} 
No que tange a Lei $n^{0}$ 11.196/o5, esta criou Regime Especial de Tributação para a Plataforma de Exportação de Serviços de Tecnologia da Informação - Repes ${ }^{46}$, onde o optante (pessoa jurídica) que exerça preponderantemente as atividades de desenvolvimento de software ou de prestação de serviços de tecnologia da informação e que assuma compromisso de exportação igual ou superior a 50\% (cinquenta por cento) de sua receita bruta anual decorrente da venda dos bens e serviços ${ }^{47}$, serão excluídos os impostos e contribuições incidentes sobre a venda.

É criado, também, o Regime Especial de Aquisição de Bens de Capital para Empresas Exportadoras - Recap ${ }^{48}$.

Nesse regime o beneficiário é pessoa jurídica preponderantemente exportadora, sendo aquela cuja receita bruta decorrente de exportação para o exterior, no ano-calendário imediatamente anterior à adesão ao Recap, houver sido igual ou superior a 50\% (cinquenta por cento) de sua receita bruta total de venda de bens e serviços no período e que assuma compromisso de manter esse percentual de exportação durante o período de 2 (dois) anoscalendário, terá excluídos os impostos e contribuições incidentes sobre a venda ${ }^{49}$.

Ainda instituiu os seguintes incentivos fiscais para a inovação tecnológica, do qual a pessoa jurídica poderá se beneficiar:

I - dedução, para efeito de apuração do lucro líquido, de valor correspondente à soma dos dispêndios realizados no período de apuração com pesquisa tecnológica e desenvolvimento de inovação tecnológica classificáveis como despesas operacionais pela legislação do Imposto sobre a Renda da Pessoa Jurídica - IRPJ ou como pagamento na forma prevista no § 20 deste artigo;

II - redução de 50\% (cinqüenta por cento) do Imposto sobre Produtos Industrializados - IPI incidente sobre equipamentos, máquinas, aparelhos e instrumentos, bem como os acessórios sobressalentes e ferramentas que acompanhem esses bens, destinados à pesquisa e ao desenvolvimento tecnológico;

III - depreciação integral, no próprio ano da aquisição, de máquinas, equipamentos, aparelhos e instrumentos, novos, destinados à utilização nas atividades de pesquisa tecnológica e desenvolvimento de inovação tecnológica, para efeito de apuração do IRPJ e da CSLL; (Redação dada pela Lei no ${ }^{0} 11.774$, de 2008);

IV - amortização acelerada, mediante dedução como custo ou despesa operacional, no período de apuração em que forem efetuados, dos dispêndios relativos à aquisição de bens intangíveis, vinculados exclusivamente às atividades de pesquisa

\footnotetext{
${ }^{46}$ Art. 1ㅇ da Lei no 11.196/05.

${ }^{47}$ Art. 20 da Lei no 11.196/05.

${ }^{48}$ Art. 12 da Lei no 11.196/05.

${ }^{49}$ Art. 13 da Lei no 11.196/05.
} 
tecnológica e desenvolvimento de inovação tecnológica, classificáveis no ativo diferido do beneficiário, para efeito de apuração do IRPJ;

V - (Revogado pela de Medida Provisória ${ }^{\circ}$ 497, de 2010);

VI - redução a o (zero) da alíquota do imposto de renda retido na fonte nas remessas efetuadas para o exterior destinadas ao registro e manutenção de marcas, patentes e cultivares ${ }^{50}$.

Por fim, a lei em tela criou o programa de inclusão digital, onde reduzidas a o (zero) as alíquotas da Contribuição para o PIS/Pasep e da COFINS incidentes sobre a receita bruta de venda a varejo de diversos produtos, como telefones portáteis de redes celulares que possibilitem o acesso à internet em alta velocidade, equipamentos terminais de clientes (roteadores digitais), entre outros.

\section{CONSIDERAÇÕES FINAIS}

No bojo do conteúdo apresentado, afere-se que os incentivos fiscais é um instrumento de extrafiscalidade imanente, constituidora de uma normatividade indutora, por incentivar ou desestimular certas condutas do cidadão, o qual pode ser utilizado afetando tanto a receita pública, por meio de isenções, diferimentos, remissão e anistia, quanto a despesa pública, por meio de subvenções, créditos presumidos e subsídios.

Nesse leque de possibilidades para a constituição dos incentivos fiscais é palmar que o seu uso só se legitima quando calcados nos valores máximos constituidores do plexo normativo constitucional, seja na sua veiculação por meio de lei (princípio da legalidade), bem como um instrumento de promoção do universo de normas constitucionais programáticas, no que tange, por exemplo, aos incentivos à cultura, a tecnologia, ao desenvolvimento, a saúde, tendo por norteador de sua aplicabilidade o princípio da isonomia, com o fito de evitar os benefícios odiosos, para favorecimento de poucos em detrimento do universo dos cidadãos brasileiros.

É certo, que o presente trabalho não tem por escopo esmiuçar em profundida abissal os meandros dos incentivos fiscais, de sorte a identificar e analisar quais as melhores modalidades de incentivos fiscais e em que circunstâncias fáticas.

Mas sim levantar considerações gerais, no que tange a juridicidade do mesmo, acreditando que este é um dos mais fortes instrumentos, que caso seja manejado dentro dos termos éticos, tendo em vista a transparência e o accountably, pode transformar a almejada realidade do

50 Art. 17 da Lei no 11.196/05. 
“dever-ser”, da constituição cidadã, na realidade do "ser”, granjeando, assim, a efetivação de diversos direitos fundamentais do carente cidadão brasileiro ${ }^{51}$.

(...) Infelizmente, como ressaltado por Boaventura de Souza Santos, constatamse a 'erosão de eficácia do Estado na gestão macro-econômica' e o aumento das desigualdades entre o Norte e o Sul. Enquanto um quarto da população mundial vive em pobreza absoluta, ' $15 \%$ da população mundial produziu e consumiu $70 \%$ do rendimento mundial'. Fortalecimento no sistema de incentivos, auxílios e subsídios, desde que não canalizados para que as grandes empresas poupem seus capitais e desde que haja rigoroso sistema de fiscalização, podem ser os únicos caminhos para alteração desse preocupante quadro (CAVALCANTE, 2007, p. 192).

\section{REFERÊNCIAS BIBLIOGRÁFICAS}

Becher, A. A. (2007). Teoria Geral do Direito Tributário (4º ed.). São Paulo: Noesis.

Borges, J. S. (2011). Teoria geral da isenção tributária ( $3^{\circ}$ ed.). São Paulo: Malheiros.

Canotilho, J. J., Leoncy, L. F., Mendes, G. F., Sarlet, I. W., \& Streck, L. L. (2013). Comentários à Constituição do Brasil. São Paulo: Saraiva.

Carrazza, R. A. (2013). Curso de Direito Constitucional Tributário (29º ed.). São Paulo: Malheiros.

Carvalho, P. d. (2009). Curso de Direito Tributário (21ํed.). São Paulo: Saraiva.

Catão, M. A. (2004). Regime jurídico dos incentivos fiscais. Rio de Janeiro: Renovar.

Cavalcante, F. d. (2007). Considerações sobre incentivos fiscais e globalização. Em I. G. Artins, A. Elali, \& M. M. Peixoto, Incentivos Fiscais. São Paulo: MP.

\footnotetext{
51 “A concessão de incentivos não é simplesmente uma forma de intervenção do Estado na economia privada. Deve ser entendida, isto sim, como um canal capaz de promover, em última instância, o desenvolvimento em sua face mais humana, que é a de agregar qualidade de vida à população, seja através da criação de empregos, do acesso à cultura, da geração e redistribuição da renda ou de quaisquer outros meios lícitos" (PIRES, 2007, p. 35).
} 
Elali, A. (2007). Incentivos fiscais, neutralidade e desenvolvimento econômico. Em I. G. Martins, A. Elali, \& M. M. Ppeixoto, Incentivos Fiscais. São Paulo: MP editora.

Elali, A. (2007). Tributação e regulação econômica - um exame da tributação como instrumento de regulação econômica na busca da redução das desigualdades regionais. São Paulo: MP editora.

Elali, A. (2010). Incentivos fiscais internacionais: concorrência fiscal, mobilidade financeira e crise do Estado. São Paulo: Quartier Latin.

Estigara, A., Pereira, R., \& Lewis, S. A. (2009). Responsabilidade Social e incentivos fiscais. São Paulo: Atlas.

Faria, J. E. (2004). O direito na economia globalizada. São Paulo: Malheiros.

Machado, H. d. (2010). Curso de Direito Tributário (31ํ ed.). São Paulo: Malheiros.

MELO, F. S. (2007). Incentivos fiscais e segurança jurídica. Em I. G. Aatins, A. Elali, \& M. M. Peixoto, Incentivos Fiscais. São Paulo: MP.

Melo, J. E. (2012). ICMS - Teoria e Prática (12º ed.). São Paulo: Dialética.

Oliveira, R. F. (2010). Curso de Direito Financeiro ( $3^{\circ}$ ed.). São Paulo: RT.

Paula, A. S. (jul./set de 2004). Ciência e tecnologia nas Constituições brasileiras: breve comparativo com as Constituições estrangeiras. Revista de Direito Constitucional Internacional.

Paulsen, L. (2007). Direito tributário - Constituição e Código Tributário à luz da doutrina e da jurisprudência ( $9^{\circ}$ ed.). Porto Alegre: Livraria do Advogado.

Paulsen, L. (2014). Curso de Direito Tributário (6º ed.). Porto Alegre: Livraria do Advogado.

Pires, A. R. (2001). Práticas abusivas no comércio internacional. Rio de Janeiro: Forense.

Pires, A. R. (2007). Ligeiras reflexões sobre a questão dos incentivos fiscais no Brasil. Em I. G. Martins, A. Elali, \& M. M. Peixoto, Incentivos Fiscais. São Paulo: MP. 
Santos, A. C. (2003). Auxílios de Estado e fiscalidade. Coimbra: Almedina.

Schoieri, L. E. (2005). Normas tributárias indutoras e intervenção econômica. Rio de Janeiro: Forense.

Schoieri, L. E. (2013). Direito Tributário ( $3^{\circ}$ ed.). São Paulo: Saraiva.

Silva, E. N., \& Motta Filho, M. M. (2010). Outras formas desonerativas. Em I. G. Martins, A. Elali, \& M. M. Peixoto, Curso de Direito Tributário São Paulo (12º ed.). São Paulo: Saraiva.

Torres, R. L. (out de 2005). Anulação de incentivos fiscais - efeito no tempo. Revista Dialética de Direito Tributário, 121.

\section{CURRICULUM VITAE}

\section{Rocco Antonio Rangel Rosso Nelson}

Especialista em Direito e Cidadania pela Escola Superior do Ministério Público. Especialista em Direito Penal e Criminologia pela Universidade Potiguar. Mestre em Direito Constitucional pela UFRN. Ex-professor do curso de direito e de diversos cursos tecnológicos e da pósgraduação do Centro Universitário FACEX. Professor de Direito do Instituto Federal do Rio Grande do Norte - IFRN, Câmpus João Câmara.

rocconelson@hotmail.com 